\title{
Expectation About Complete Dentures Among Patients -A Questionnaire Based Study
}

\author{
Ashwin Shravan Kumar ${ }^{1}$, Revathi Duraisamy ${ }^{2}$ and Dhanraj Ganapathy ${ }^{3}$ \\ ${ }^{1}$ Saveetha Dental College and Hospitals, Saveetha Institute of Medical and Technical \\ Sciences, Saveetha University, Chennai- 600077, India \\ Assistant Professor, Department of Prosthodontics, Saveetha Dental College and Hospitals, Saveetha \\ Institute of Medical and Technical Sciences, Saveetha University, Chennai - 600077, India \\ ${ }^{3}$ Professor and Head, Department of Prosthodontics, Saveetha Dental College and Hospitals, \\ Saveetha Institute of Medical and Technical Sciences, Saveetha University, Chennai, India
}

\section{ABSTRACT}

The main function of the stomatognathic system is to provide support for mastication, aesthetic appearance and assist phonetics. If there occurs loss of teeth due to pathologic or physiologic reason there would be loss of all these properties. Therefore the replacement of lost teeth by artificial prosthetic means play a major role in the oral as well as general health of patients as they help them both to meet the physiological and psychological needs.The aim of this study was to analyze the various parameters of expectation among patients and the dentures delivered to them. A questionnaire-based survey consisting of 15 questions was circulated.100 participants who were undergoing/underwent complete denture treatment were included in the study. Responses were tabulated and Chi-square analysis was performed using SPSS software version. The results showed that there is a difference in the expectation of the treatment among various groups which needs to be considered prior to treatment planning. P value was found to be $<0.05$ indicating a statistically significant difference in the expectations regarding the outcome, the difficulties faced during the treatment, opinion regarding the expenses, and willingness towards treatment among the patients of different age categories.Within the limitation of study it can be said that the patients included in this study were provided treatment based on their expectations and they were satisfied with this holistic approach.Further such studies to be done on different geographic locations and different populations to have a clear conclusion about the expectations. Such considerations can enhance good oral hygiene and positive psychological effects on patients towards oral habits.

KEY WORDS: COMPLETE DENTURE; TREATMENT; EXPECTATIONS; PATIENTS; OUTCOMES.

\section{ARTICLE INFORMATION}

*Corresponding Author: revathid.sdc@saveetha.com

Received 5th Aug 2020 Accepted after revision 23rd Sep 2020

Print ISSN: 0974-6455 Online ISSN: 2321-4007 CODEN: BBRCBA

Thomson Reuters ISI Web of Science Clarivate Analytics USA and Crossref Indexed Journal

$$
\begin{aligned}
& \text { Clarivate } \\
& \text { Analytics }
\end{aligned}
$$

NAAS Journal Score 2020 (4.31) SJIF: 2020 (7.728)

A Society of Science and Nature Publication,

Bhopal India 2020. All rights reserved.

Online Contents Available at: http//www.bbrc.in/

Doi: $h t t p: / / d x$.doi.org/10.21786/bbrc/13.8/137 


\section{INTRODUCTION}

The main function of the stomatognathic system is to provide support for mastication, aesthetic appearance and assist phonetics. If there occur, loss of teeth due to pathologic or physiologic reason there would be loss of all these properties(Allen and McMillan, 2003). There will also be loss of alveolar bone which might reduce the vertical dimensions of face (Felton, 2009). Therefore the replacement of loss teeth by artificial prosthetic means play a major role in the oral as well as general health of patients as they help them to meet both the physiological and psychological needs(Douglass, Shih and Ostry, 2002).

The number of patients undergoing complete denture treatment has been increased about 10\% in the past decade. There has been varied ideologies among patients regarding the treatment as there are different treatment protocols that are customizable by the dental health care provider based on the needs of the patients. The quantity of the treatment cannot be a justification for the success of this treatment. The successful outcome requires the quality of work, the demands and the expectations of the patient and the satisfaction of the patient towards the treatment delivered (Jonkman, Waas and Kalk, 1995; Muller, Heath and Ott, 2002; Carlsson and Omar, 2010).

There have been a lot of literature statements regarding the expectations and outcomes. Several researchers have undertaken statistics across the globe in different time periods and studies have shown results similar to those quoted in literature, however there have been certain differences in all these cases which need to be addressed (Smith and McCord, 2004).The expectations and outcome should not always be related with esthetics,comfort,associated pain,irritation,occlusion etc. Also it should account for the time taken for the procedure,cost and necessity. All these parameters should be considered for estimating overall satisfaction among the patients (Laird, 1987; Fenlon, Sherriff and Newton, 2007). Patients do think complete dentures as a complete replacement of natural teeth by artificial means where they are specific in customization. The requirement is not unique for all people of both the gender nor do their expectations. Thus it is important for the dentist to have a clear perception and evaluation of each patient before starting a complete denture treatment (Kemnitzer, 1956; Krausch-Hofmann et al., 2018).

There have been a lot of advancements in this procedure but the outcomes were not that pleased by patients.There has been certain complaints regarding time,cost,fit,maintenance in these procedures(Soni, Kumar and Shukla, 2016). In countries like India with the increasing demand for this treatment it is a prime responsibility for a dental professional to ensure that the treatment has been done at a satisfactory level for the patient. The results were not pleasing especially due to financial constraints and the dentist not being able to prioritize the patient requirements.Such kinds of remarks were stated in many literature. Hence the treatment modality should take into consideration all the factors influencing the outcome which includes systemic health, financial status, perception towards treatment apart from local factors (Kalk and Baat, 1990; Bhat, D. and Malli, 2014). Previously our department has published extensive research on various aspects of prosthetic dentistry ("Evaluation of Corrosive Behavior of Four Nickel-chromium Alloys in Artificial Saliva by Cyclic Polarization Test:An in vitro Study', 2017; Ganapathy, Kannan and Venugopalan, 2017; Jain, 2017a, 2017b; Ranganathan, Ganapathy and Jain, 2017; Ariga et al., 2018; Gupta, Ariga and Deogade, 2018; Anbu et al., 2019; Ashok and Ganapathy, 2019; Varghese, Ramesh and Veeraiyan, 2019), this vast research experience has inspired us to analyze the various parameters of expectation among patients and the dentures delivered to them.

Table 1. Questionnaire

Section I

Are you willing to attend this survey?

Are you willing to use these data for educational and research purposes?

Can you declare that all the responses were true to your knowledge?

Section II

Name

Age/Gender

Section III

Have you completed the treatment course entirely?

What is your expectation regarding complete denture treatment?

What is your opinion regarding the expenses for the treatment?

Any previous experience of the procedure?

Were you willing for the treatment or you have been convinced for the treatment?

What do you consider the major difficulty faced during the course of treatment?

Do you feel difficulties in wearing the dentures that were delivered?

Do you feel any difficulties in maintaining the dentures?

Are you satisfied with the treatment provided?

Would you recommend people regarding the need for this treatment?

\section{MATERIAL AND METHODS}

Study type and setting: This is a questionnaire based study and data were collected by reviewing the response of participants. Participants who were treated / undergoing complete denture treatment in Saveetha Dental College and Hospitals were included and others were excluded. The total sample size was 100 which accounted for 66 male and 34 female patients. A set of 15 questions were prepared. The questionnaire consists 
of III sections which includes the patient's consent to participate, followed by their general details (Name/Age /Gender) and the final section includes the expectations and difficulties faced and the satisfaction towards the outcome. The individual questions of each section are represented in Table-1.

Sampling and verification: All data were obtained and are approved by the Institutional Ethical Committee and cross-verified by 2 reviewers. Subjective sampling was done. The external and internal validity were applicable.

Data analysis: All data retrieved were compiled in an excel sheet and imported to SPSS by IBM for statistical analysis. Chi-square statistical analysis was performed and the independent variables include age and gender and dependent variables include their responses for each question respectively.

Figure 1: Pie Chart representing the age category of the participants. 46 participants were of the group 5060 years(Green) followed by 40 participants below 50 years(Blue), 9 participants between 60-70 years(Grey) and 5 participants of the age group 70-80(Violet).

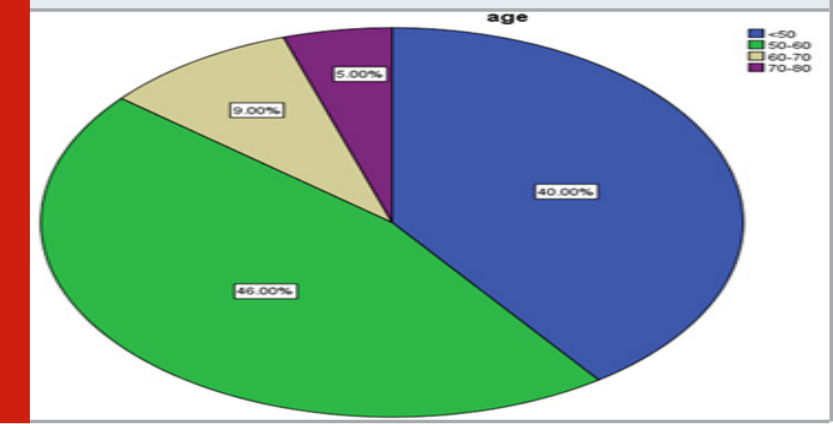

Figure 2: Pie Chart representing the gender of the participants. The total study population included 100 participants of which 66 were males(Green) and 34 were females (Blue).

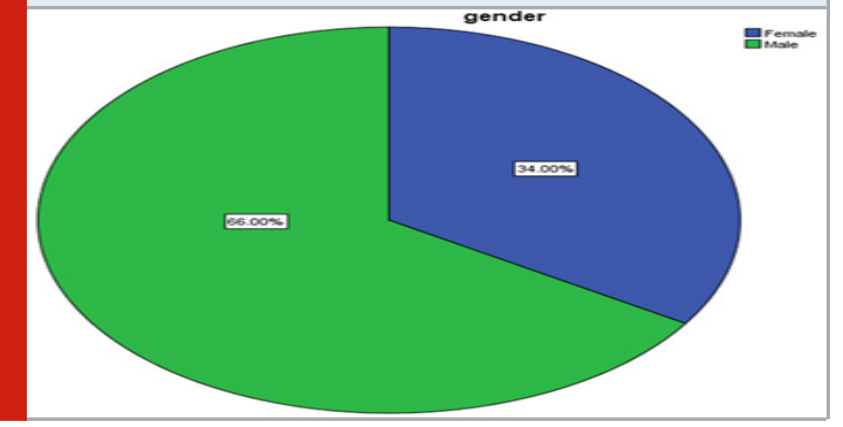

RESULTS AND DISCUSSION

From Figure-1 representing the age group of the participants it can be seen that $46 \%$ of participants were between the age 50-60 followed by $40 \%$ of them being $<50$ years of age. Irrespective of the age group it can be seen that $66 \%$ majority of the participants were males which is shown in Figure-2. This is in consensus with other studies stating that geriartic dentistry has been showing male predilection for replacement of missing teeth than their counterpart(Widbom, Soderfeldt and Kronstrom, 2005). It can be seen from Figure- 3 that in the age categories $<50$ and 50-60 around $70 \%$ of the participants had completed their treatment course.

Figure 3: Pie chart representing the patients undergone complete treatment protocol, where $84 \%$ of the population had completed the treatment(Green) whereas $16 \%$ of them were still undergoing treatment.(Blue-No).

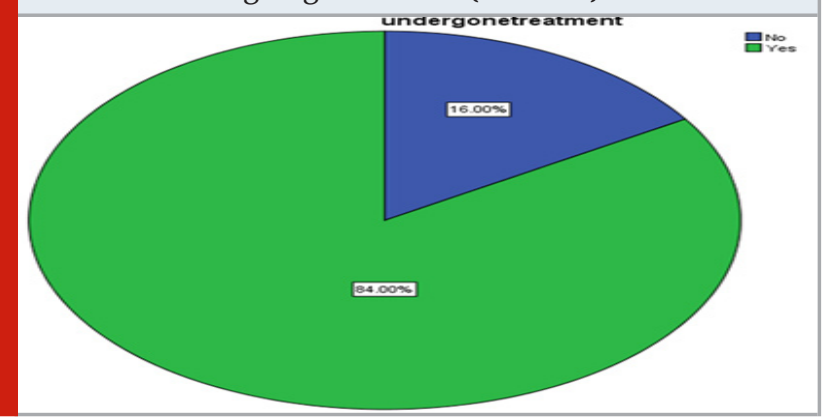

Figure 4: Bar graph representing the association between age group of patients and their expectations regarding treatment outcome, where $\mathrm{X}$-axis represents the age categories $(<50,50-60,60-70,70-80), Y$ axis represents number of responses regarding expectations of treatment outcome (Blue-Aesthetics, Green- All, Grey- Comfort, Violet- Fit). Chi square test was performed and there was found to be a statistically significant association as $p$ value was found to be 0.001 i.e $\mathrm{p}<0.05$. Hence proving the majority of patients in the age group 50-60 years preferred aesthetics as the major expectation than other criterias.

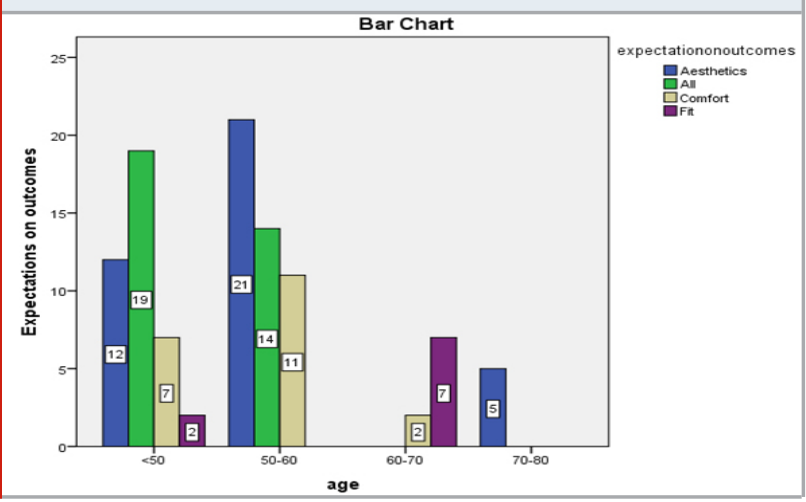

From Figure-4 it can be stated that around 60\% of participants in the age group $<50$ were expecting an outcome consisting of proper aesthetic value, functional fit and comfortability. Whereas the majority in the age group around 50-60 stated that aesthetics were their major concern which was in correlation with the expectation among patients $>70$ years old . Interestingly the majority of the participants of age group 60-70 picked up that proper fitting dentures as their major expectations. This shows that there are multiple parameters to be considered before treatment as it might 
have an impact towards treatment. Also from Figure- 5 it can be stated that majority of the participants around $80 \%$ in the age categories above 50 were considering this treatment as a cheaper one whereas the age category < 50 felt it as a comparatively costlier treatment.This shows that the socioeconomic status and other factors do have an impact in health care (McCunniff et al., 2017; Turgut Cankaya, Yurdakos and Gokalp Kalabay, 2020).

Figure 5: Bar graph representing the association between age group of patients and their feedback towards expense of treatment, where $\mathrm{X}$-axis represents the age categories $(<50,50-60,60-70,70-80), Y$ axis represents number of responses on feedback towards expense of treatment (Blue-Cheap, Green- Costly). Chi square test was performed and there was found to be a statistically significant association as $p$ value was found to be 0.002 i.e $p<0.05$. Hence proving that the majority of participants in the age category 50-60 years considered the treatment to be cheaper than others.

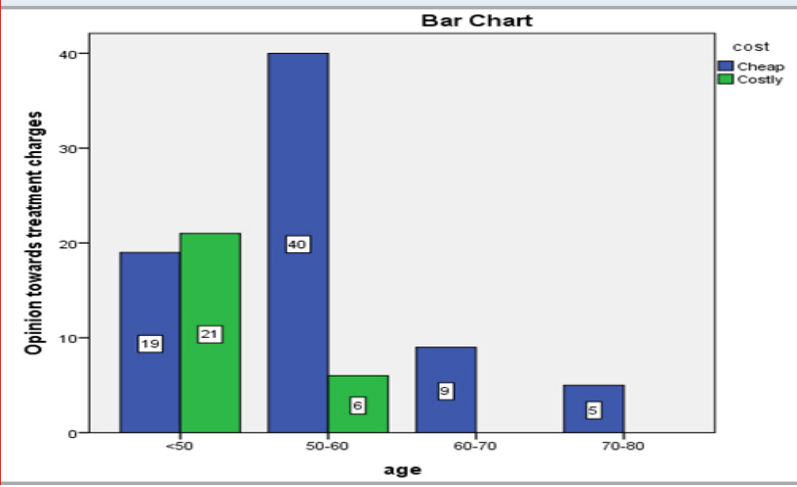

Figure 6: Bar graph representing the association between age groups of patients and their feedback towards previous experience, where $\mathrm{X}$-axis represents the age categories $(<50,50-60,60-70,70-80), Y$ axis represents number of responses on feedback towards previous experience (Blue-No, Green- Yes). Chi square test was performed and there was found to be a statistically significant association as $p$ value was found to be 0.012 i.e $\mathbf{p}<0.05$. Hence proving that majority of participants of the age group 50-60 years had a previous experience with treatment than others.

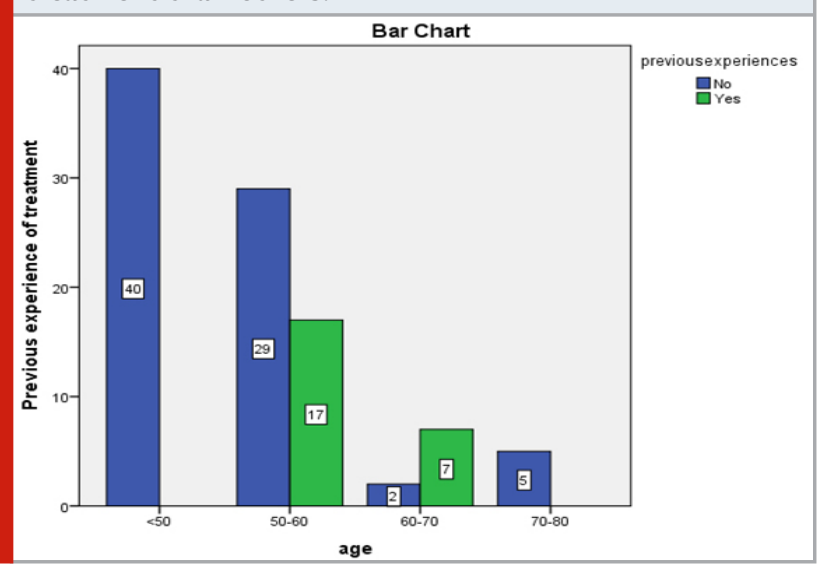

Previous experiences of any treatment has a significant relationship towards the patients mentality.It might have a positive approach to support or may possess a threat. But in case of a treatment preferred for the first time, the patients are not aware of what would be the possible outcome and hence there needs a convincing approach by the dental practitioner to deliver the treatment. This is represented in Figure-6 \& Figure-7.

Figure 7: Bar graph representing the association between age group of patients and their feedback towards willingness, where $X$-axis represents the age categories $<<50,50-60$, 60-70, 70-80), Y axis represents number of responses on feedback towards willingness (Blue-Convinced, GreenWilling). Chi square test was performed and there was found to be a statistically significant association as $p$ value was found to be 0.022 i.e $p<0.05$. Hence proving that majority of participants of age category 50-60 were convinced for the treatment than others.

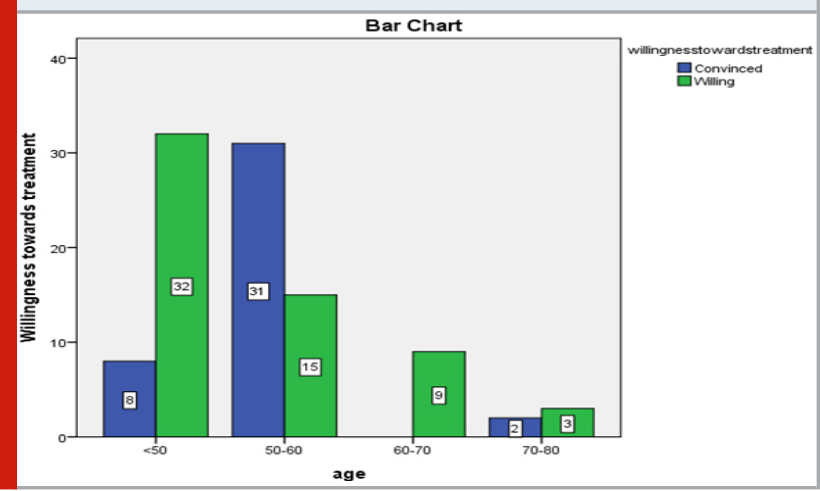

Figure 8: Bar graph representing the association between age group of patients and their feedback towards difficulty faced during treatment, where $\mathrm{X}$-axis represents the age categories $(<50,50-60,60-70,70-80), \mathrm{Y}$ axis represents number of responses on feedback towards difficulty faced during treatment (Blue-Multiple appointments, Green- Time, Grey-Travel expenses). Chi square test was performed and there was found to be a statistically significant association as $p$ value was found to be 0.003 i.e $\mathrm{p}<\mathbf{0 . 0 5}$. Hence proving that majority of participants of the age category 50-60 years had considered time consumption was the major difficulty faced during the treatment than others.

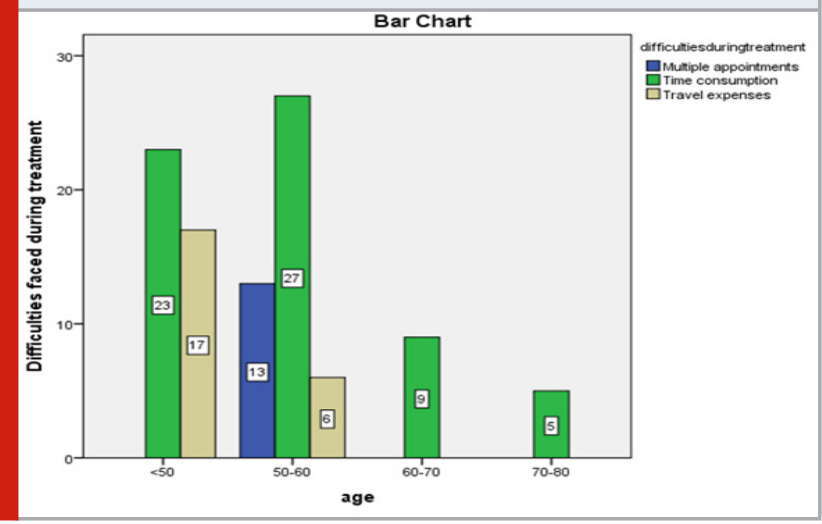


All these parameters were based on their expectations. There are other factors too that play a significant and equally important role in the success of treatment. Those include the difficulties during the treatment, post treatment difficulties with the delivered dentures including the adaptability, maintenance etc. From Figure-8 it can be said that the vast majority around $80 \%$ of the total participants indicated that major difficulty faced during the treatments was the prolonged operative time in the dental chair. Around $90 \%$ of the participants had no difficulty regarding the fitting or maintenance of the delivered dentures in almost all the age categories which is represented in the Figure-9 \& Figure-10.

Figure 9: Bar graph representing the association between age group of patients and their feedback towards difficulty faced during wearing of dentures, where $\mathrm{X}$-axis represents the age categories $(<50,50-60,60-70,70-80), Y$ axis represents number of responses on feedback towards difficulty faced during wearing of dentures (Blue-No, Green-Yes). Chi square test was performed and there was no statistically significant association as $p$ value was found to be 0.23 i.e $p>0.05$. However, the majority of participants in the age category 50-60 years had no difficulty in wearing dentures.

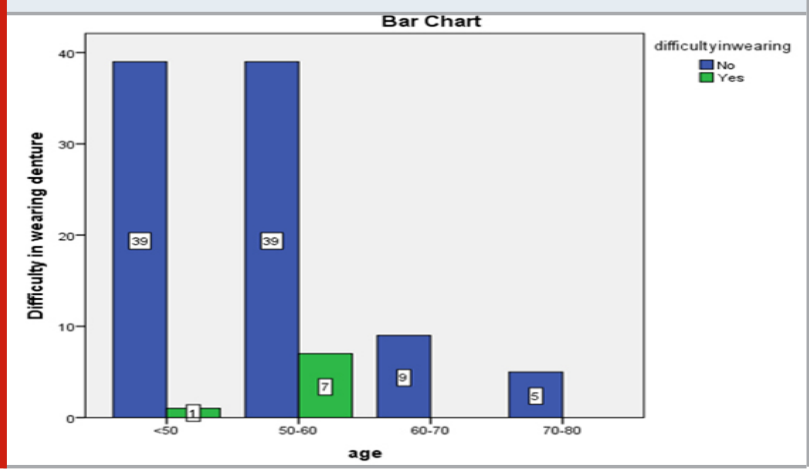

Figure-10: Bar graph representing the association between age group of patients and their feedback towards difficulty faced during maintaining of dentures, where $\mathrm{X}$-axis represents the age categories $(<50,50-60,60-70,70-$ 80 ), $\mathrm{Y}$ axis represents number of responses on feedback towards difficulty faced during maintaining of dentures (Blue-No, Green-Yes). Chi square test was performed and there was no statistically significant association as $p$ value was found to be 0.23 i.e $p>0.05$. However, the majority of participants in the age category 50-60 years had no difficulty in maintaining dentures.

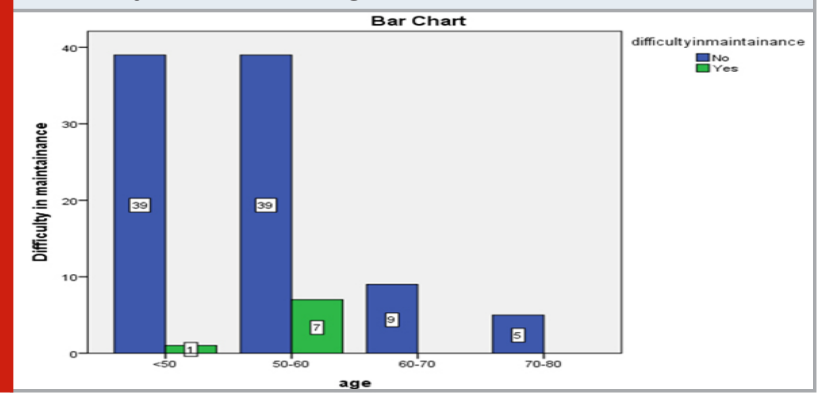

Figure 11: Bar graph representing the association between age group of patients and their feedback towards satisfaction of treatment, where $\mathrm{X}$-axis represents the age categories $(<50,50-60,60-70,70-80), Y$ axis represents number of responses on feedback towards satisfaction of treatment (Blue-No, Green-Yes). Chi square test was performed and there was no statistically significant association as $\mathrm{p}$ value was found to be 0.13 i.e $\mathrm{p}>0.05$. However majority of the patients in the age group 50-60 years were satisfied with the outcome of the treatment.

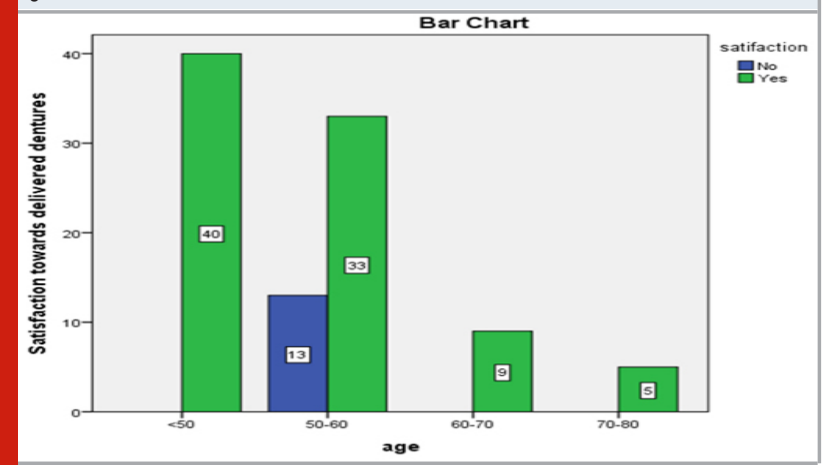

Figure 12: Bar graph representing the association between age group of patients and their feedback regarding recommendations for the treatment, where $\mathrm{X}$-axis represents the age categories $(<50,50-60,60-70,70-80), Y$ axis represents number of responses on feedback towards recommendations for the treatment (Blue-No, GreenYes). Chi square test was performed and there was no statistically significant association as $p$ value was found to be 0.13 i.e $p>0.05$. However, majority of participants of the age category 50-60 years were ready to recommend the treatment than others.

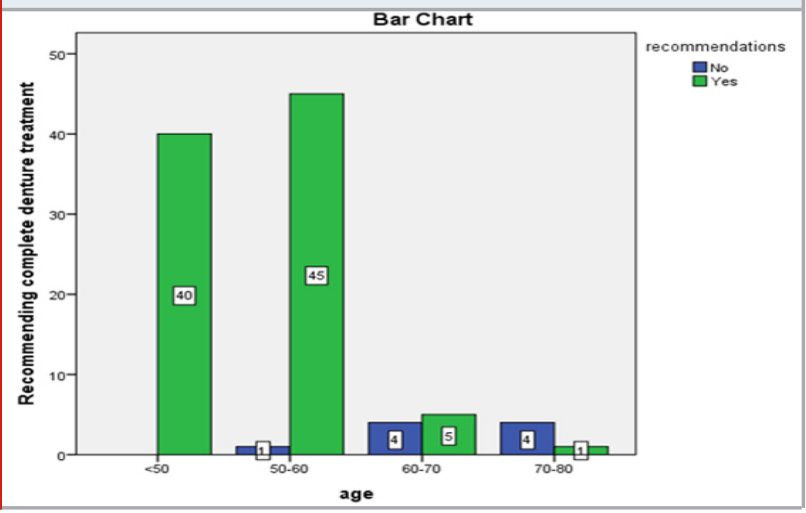

Despite various difficulties encountered like the multiple appointments, travel expenses and being convinced for treatment, it can be seen that around $85 \%$ of participants were satisfied with the overall outcome and were met with their expectations (Figure-11). This patient satisfaction is not only a part of work ethic but also plays a major role in the promotion of geriartic health care among the general public as many were ready to recommend the need of complete denture treatment to their close vicinity, this is represented in Figure-12. 
It has been emphasised that patient satisfaction is the key for maintaining good oral health.Various factors have been controlling these satisfaction,irrespective of gender and age. Every patient has a prime requirement of good fitting denture which serves at its best for masticatory and other functions(Assunção et al., 2009; Chowdhary, Singh and Mishra, 2019; Duraisamy et al., 2019).

In most cases there has been very little attention given to psychological expectation on dentures (Zarb, 2013; Bakar, 2015). Difficulties in accepting dentures is multifactorial which includes compromisation of proper function, phonetics,aesthetics etc(Zou and Zhan, 2015). But it does not halt with these factors alone. As discussed in this topic it includes other non specific factors. One of the major factors influencing treatment is the socioeconomic status which plays a vital role in deciding the treatment plan and meeting the demands.

The dentist should make the patient aware and adjust to the circumstances accordingly. It is the duty of the dental practitioner to avoid over expectations and prioritize the demands and needs in providing prosthetic care(Singh and Saini, 2016; Awadalkreem et al., 2020). Similar study were conducted under different researchers and several factors came out of basic necessities of patients towards complete denture(Bellini et al., 2009; Gaspar et al., 2013; Siqueira et al., 2013; Silva et al., 2014)(Yamaga, Sato and Minakuchi, 2013; Soeda et al., 2017).

Many other extra factors like the difficulties during the course of treatment, opinion on the expenses towards treatment, willingness towards treatment were also considered in this study which were not found in other studies(Perea et al., 2013; Madhuri et al., 2014; Karmacharya, Saha and Kumari, 2017; Yamaga et al., 2019). The limitations of this study includes certain factors like systemic health of the patients, occupation and location, gender based association of expectations etc are not included in this study. All these parameters can be included in future studies to get an holistic approach.

\section{CONCLUSION}

Within the limitations of this study, it is evident that expectation of patients about dentures is an important aspect in treatment of completely edentulous patients. This aspect is least considered among many dental practitioners whereas the patients in this study had been considered their various demands and expectations and thus the patients were happy regarding the outcome. Further such studies to be done on different geographic locations and different populations to have a clear conclusion about the expectations. Such considerations can enhance good oral hygiene and positive psychological effects on patients towards oral habits.

\section{ACKNOWLEDGMENTS}

I would like to thank our Director sir for giving me an opportunity to do this research work and also to my guide and mentor.

\section{Conflict of Interest: None Declared}

\section{REFERENCES}

Allen, P. F. and McMillan, A. S. (2003) 'A longitudinal study of quality of life outcomes in older adults requesting implant prostheses and complete removable dentures', Clinical Oral Implants Research, pp. 173-179. doi: 10.1034/j.1600-0501.2003.140206.x.

Anbu, R. T. et al. (2019) 'Comparison of the Efficacy of Three Different Bone Regeneration Materials: An Animal Study', European journal of dentistry, 13(1), pp. 22-28.

Ariga, P. et al. (2018) 'Determination of Correlation of Width of Maxillary Anterior Teeth using Extraoral and Intraoral Factors in Indian Population: A Systematic Review', World Journal of Dentistry, 9(1), pp. 68-75.

Ashok, V. and Ganapathy, D. (2019) 'A geometrical method to classify face forms', Journal of oral biology and craniofacial research, 9(3), pp. 232-235.

Assunção, W. G. et al. (2009) 'A comparison of patient satisfaction between treatment with conventional complete dentures and overdentures in the elderly: a literature review', Gerodontology, pp. 154-162. doi: 10.1111/j.1741-2358.2009.00299.x.

Awadalkreem, F. et al. (2020) 'The Influence of Immediately Loaded Basal Implant Treatment on Patient Satisfaction', International Journal of Dentistry, pp. 1-10. doi: 10.1155/2020/6590202.

Bellini, D. et al. (2009) 'Patients' expectations and satisfaction of complete denture therapy and correlation with locus of control', Journal of Oral Rehabilitation, pp. 682-686. doi: 10.1111/j.1365-2842.2009.01967.x. Bhat, V. S., D., K. P. and Malli, P. (2014) 'A SURVEY TO ASSESS PATIENT SATISFACTION AFTER RECEIVING COMPLETE DENTURE PROSTHESES IN A.B. SHETTY MEMORIAL INSTITUTE OF DENTAL SCIENCES', Journal of Health and Allied Sciences NU, pp. 081-085. doi: 10.1055/s-0040-1703768.

Carlsson, G. E. and Omar, R. (2010) 'The future of complete dentures in oral rehabilitation. A critical review', Journal of Oral Rehabilitation, pp. 143-156. doi: 10.1111/j.1365-2842.2009.02039.x.

Chowdhary, R., Singh, S. and Mishra, S. (2019) 'Patient expectations and satisfaction with conventional complete dentures: a systematic review', Tanta Dental Journal, p. 55. doi: 10.4103/tdj.tdj_2_19.

Douglass, C. W., Shih, A. and Ostry, L. (2002) 'Will there be a need for complete dentures in the United States in 2020?', The Journal of Prosthetic Dentistry, pp. 5-8. doi: $10.1067 / \mathrm{mpr} .2002 .121203$. 
Duraisamy, R. et al. (2019) 'Compatibility of Nonoriginal Abutments With Implants: Evaluation of Microgap at the Implant-Abutment Interface, With Original and Nonoriginal Abutments', Implant dentistry, 28(3), pp. 289-295.

Evaluation of Corrosive Behavior of Four Nickelchromium Alloys in Artificial Saliva by Cyclic Polarization Test:An in vitro Study' (2017) World Journal of Dentistry, 8(6), pp. 477-482.

Felton, D. A. (2009) 'Edentulism and comorbid factors', Journal of prosthodontics: official journal of the American College of Prosthodontists, 18(2), pp. 88-96.

Fenlon, M. R., Sherriff, M. and Newton, J. T. (2007) 'The influence of personality on patients' satisfaction with existing and new complete dentures', Journal of Dentistry, pp. 744-748. doi: 10.1016/j. jdent.2007.06.003.

Ganapathy, D. M., Kannan, A. and Venugopalan, S. (2017) 'Effect of Coated Surfaces influencing Screw Loosening in Implants: A Systematic Review and Meta-analysis', World Journal of Dentistry, 8(6), pp. 496-502.

Gaspar, M. G. et al. (2013) 'Correlation of previous experience, patient expectation and the number of postdelivery adjustments of complete dentures with patient satisfaction in a Brazilian population', Journal of Oral Rehabilitation, pp. 590-594. doi: 10.1111/joor.12070. Gupta, P., Ariga, P. and Deogade, S. C. (2018) 'Effect of Monopoly-coating Agent on the Surface Roughness of a Tissue Conditioner Subjected to Cleansing and Disinfection: A Contact Profilometric Study', Contemporary clinical dentistry, 9(Suppl 1), pp. S122S126.

Jain, A. R. (2017a) 'Clinical and Functional Outcomes of Implant Prostheses in Fibula Free Flaps', World Journal of Dentistry, 8(3), pp. 171-176.

Jain, A. R. (2017b) 'Prevalence of Partial Edentulousness and Treatment needs in Rural Population of South India', World Journal of Dentistry, 8(3), pp. 213-217. Jonkman, R. E. G., Waas, M. A. J. and Kalk, W. (1995) 'Satisfaction with complete immediate dentures and complete immediate overdentures. A 1 year survey', Journal of Oral Rehabilitation, pp. 791-796. doi: 10.1111/j.1365-2842.1995.tb00224.x.

Kalk, W. and Baat, C. (1990) 'Patients' complaints and satisfaction 5 years after complete denture treatment', Community Dentistry and Oral Epidemiology, pp. 27-31. doi: 10.1111/j.1600-0528.1990.tb00657.x.

Karmacharya, P., Saha, S. and Kumari, M. (2017) 'Comparison of chewing ability, oral health-related quality of life, and nutritional status before and after the insertion of complete denture among edentulous patients in Lucknow', Journal of Indian Association of Public Health Dentistry, p. 145. doi: 10.4103/jiaphd. jiaphd_121_16.

Kemnitzer, D. F. (1956) 'Esthetics and the denture base', The Journal of Prosthetic Dentistry, pp. 603-615. doi: 10.1016/0022-3913(56)90004-X.

Krausch-Hofmann, S. et al. (2018) 'Predictors of Patient Satisfaction with Removable Denture Renewal: A Pilot Study', Journal of Prosthodontics, pp. 509-516. doi: 10.1111/jopr.12537.

Laird, W. R. E. (1987) 'Designing complete dentures', Journal of Dentistry, p. 88. doi: 10.1016/03005712(87)90008-x.

Madhuri, S. et al. (2014) 'Comparison of chewing ability, oral health related quality of life and nutritional status before and after insertion of complete denture amongst edentulous patients in a Dental College of Pune', Ethiopian Journal of Health Sciences, p. 253. doi: 10.4314/ejhs.v24i3.9.

McCunniff, M. et al. (2017) 'Patients' esthetic expectations and satisfaction with complete dentures', The Journal of Prosthetic Dentistry, pp. 159-165. doi: 10.1016/j.prosdent.2016.10.015.

Muller, F., Heath, M. R. and Ott, R. (2002) 'Maximum bite force after the replacement of complete dentures', Journal of Oral Rehabilitation, pp. 888-889. doi: 10.1046/j.1365-2842.2002.01026_43.x.

Perea, C. et al. (2013) 'Oral health-related quality of life in complete denture wearers depending on their socio-demographic background, prosthetic-related factors and clinical condition', Medicina Oral Patología Oral y Cirugia Bucal, pp. e371-e380. doi: 10.4317/ medoral.18648.

Ranganathan, H., Ganapathy, D. M. and Jain, A. R. (2017) 'Cervical and Incisal Marginal Discrepancy in Ceramic Laminate Veneering Materials: A SEM Analysis', Contemporary clinical dentistry, 8(2), pp. 272-278.

Bakar, O. (2015) Removable Partial Dentures: A Practitioners' Manual. Springer.

Silva, J. D. C. M. et al. (2014) 'Factors influencing patients' satisfaction with complete dentures: a qualitative study', Brazilian Dental Science, p. 83. doi: 10.14295/bds.2014.v17i2.967.

Singh, Y. and Saini, M. (2016) 'Effect of Socioeconomic Status on Expectations among Completely Edentulous Patients Regarding Conventional Complete Dentures', Journal of Gerontology \& Geriatric Research. doi: 10.4172/2167-7182.1000294.

Siqueira, G. P. de et al. (2013) 'Patients' expectation and satisfaction with removable dental prosthesis therapy and correlation with patients' evaluation of the dentists', Acta Odontologica Scandinavica, pp. 210-214. doi: 


\subsection{9/00016357.2012.654612.}

Smith, P. W. and McCord, J. F. (2004) 'What do patients expect from complete dentures?', Journal of Dentistry, pp. 3-7. doi: 10.1016/s0300-5712(03)00114-3.

Soeda, H. et al. (2017) 'A structural equation model to assess the influence of neuroticism on oral healthrelated quality of life in complete denture wearers', Gerodontology, pp. 446-454. doi: 10.1111/ger.12291. Soni, S., Kumar, M. and Shukla, M. (2016) 'A study on health consciousness among the elderly in a rural population of Katihar, Bihar', International Journal of Scientific Reports, p. 233. doi: 10.18203/issn.2454-2156. intjscirep20163111.

Turgut Cankaya, Z., Yurdakos, A. and Gokalp Kalabay, P. (2020) 'The association between denture care and oral hygiene habits, oral hygiene knowledge and periodontal status of geriatric patients wearing removable partial dentures', European oral research, 54(1), pp. 9-15.

Varghese, S. S., Ramesh, A. and Veeraiyan, D. N. (2019) 'Blended Module-Based Teaching in Biostatistics and Research Methodology: A Retrospective Study with Postgraduate Dental Students', Journal of dental education, 83(4), pp. 445-450.

Widbom, C., Soderfeldt, B. and Kronstrom, M. (2005) 'A Retrospective Evaluation of Treatments with ImplantSupported Maxillary Overdentures', Clinical Implant Dentistry and Related Research, pp. 166-172. doi: 10.1111/j.1708-8208.2005.tb00061.x.

Yamaga, E. et al. (2019) 'Relationship Between Oral Health-Related Quality of Life and Usage Period of Complete Dentures', The International Journal of Prosthodontics, pp. 327-332. doi: 10.11607/ijp.6173.

Yamaga, E., Sato, Y. and Minakuchi, S. (2013) 'A structural equation model relating oral condition, denture quality, chewing ability, satisfaction, and oral health-related quality of life in complete denture wearers', Journal of dentistry, 41(8), pp. 710-717.

Zarb, G. A. (2013) Prosthodontic Treatment for Edentulous Patients: Complete Dentures and Implantsupported Prostheses. Mosby.

Zou, Y. and Zhan, D. (2015) 'Patients' expectation and satisfaction with complete denture before and after the therapy', Vojnosanitetski pregled. Military-medical and pharmaceutical review, 72(6), pp. 495-498. 